Journal of

Language and

JLD (PRINT) ISSN 2397-2637

Discrimination

JLD (ONLINE) ISSN 2397-2645

Review

\title{
The Power of Language: How Discourse Influences Society (Second Edition) \\ By L. Young, M. Fitzgerald and S. Fitzgerald (2018) Sheffield: Equinox Publishing, 381pp.
}

Review by Mel Evans

In our current times, in which old ideological battles are being replayed across traditional print media, finding new forms and new modes of confrontation on social media platforms and passing from discourse to action in our streets, The Power of Language: How Discourse Influences Society is a pertinent and relevant textbook of interest to advanced undergraduates, postgraduates and researchers within the fields of language and linguistics. The book examines how discourse shapes our understanding of the world and suggests how a critical approach - 'looking at language reflexively... and interpretatively' - can enhance our understanding of the relationship between language and power, and thus 'the role that language plays in producing and reproducing social inequalities as they relate to issues such as health, education, race, and gender' (7-8).

The textbook, split into nine chapters, is theoretically and methodologically focussed around Systemic Functional Linguistics (SFL) and Critical Discourse Analysis (CDA). As frameworks, they are complementary and have been repeatedly shown by researchers to be highly effective at identifying 'the role of discourse in the structuring of societal relations' (xiii). The authors take great care to introduce the key concepts of these approaches systematically, using applied examples in each chapter to illustrate how SFL concepts, such as processes, participants, and circumstances (Chapter 1), textual metafunction (Chapter 4), and Hallidayan register (Chapters 4 and 7) operate in real examples of language use. Each chapter focusses on

\section{Affiliation}

University of Leicester, UK. email: mel.evans@le.ac.uk 
a particular topic and associated case studies, relevant to societal relations and social inequalities.

Chapter 1, which provides an introduction to SFL and CDA, looks at political press releases, such as that issued by then-US President Barack Obama on nuclear testing in North Korea in 2013. This chapter, like all throughout the textbook, is split into sections that provide clear working steps for the reader to apply the introduced concepts and methods. For example, Chapter 1 includes a section on 'Asking Analytical Questions', in which the authors offer a set of their own responses to the case study text, before moving onto a 'Practice' section in which readers can undertake their own analysis (in this case, looking for suggested vocabulary chains in the press release). The theory--walk-through--practise structure is an effective one, accommodating different learning styles and ensuring that both theory and method receive the required attention. The chapters conclude with a glossary of key terms introduced in that respective chapter, as well as suggestions for further reading.

The topical/thematic structure of the book works well, in terms of demonstrating the wide relevance of discourse analysis for real-life affairs and events. Chapter 2 looks at discourse of fear, using former UK Home Secretary (and subsequent Prime Minister) Theresa May's 2012 speech on immigration as an example, with a focus on the identification of processes and participants in an SFL framework. Chapter 3 examines discourse surrounding racism as a means of introducing the significance of mood and modality for CDA, using both historical and contemporary texts as evidence. In 'Language and Advertising' (Chapter 4), the linguistic topics covered are textual metafunction, cohesion, theme and rheme, exemplified with traditional print advertisements. Chapter 5 presents an overview of language within workplace communities, offering a place for readers to review and refresh their understanding of the concepts which have been covered so far.

Chapters 6-9 shift in focus to broader topics, which can be loosely classified as relating to different modes of interaction. Chapter 6 discusses Faircloughian concepts associated with modern language such as 'Technicalization' and 'Conversationalization. Chapter 7 covers 'Power in spoken language', looking at genres such as casual conversation, political interviews and courtroom discourse, to reconsider how register shapes the 'discursive choices' (232) of speakers in spoken interaction. The focus on SFL and CDA results in other spoken language features that might be considered central to power, such as turn-taking, not being covered - although question tags and repetition are included in the discussion of courtroom discourse. Non-linguistic modes of communication are

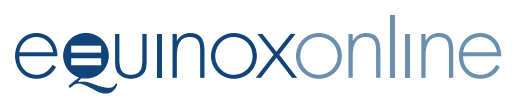


explicitly recognised in Chapter 8, in which multimodal discourse analysis is introduced by further reframing the analytical questions and approaches introduced earlier in the textbook. The final chapter, on language and social media, is a welcome inclusion, focussing on the affordances and constraints of interaction, and the role of intertextuality in the expression of ideas, using evidence from Twitter and readers' comments on news websites, such as The Guardian.

As this summary indicates, the chapters provide a thorough and detailed coverage of key concepts and methodological approaches relevant to SFL and CDA. When worked through in order, the volume should provide the reader with a well-rounded understanding of these approaches to discourse analysis, and some practical experience of analysing authentic textual evidence. However, the degree of coherence and cross-referencing across the nine chapters means that the book may be less useful as a source of standalone chapters covering particular themes (e.g. language and racism) or specific linguistic topics. Furthermore, despite the care taken to introduce the conceptual frameworks, the level of complexity suggests that the textbook is appropriate for language specialists at higher levels; undergraduate students with less linguistic experience may need a more introductory volume. Nevertheless, The Power of Language provides the reader with a lucid overview of critical linguistic approaches to discourse; the resultant skillset seems increasingly important for all of us in these current times. 